\title{
Ambient Air Pollution Exposure and Risk of Developmental Delay in Children and Teenagers in Taiwan
}

\author{
Hung-Lin Chen ${ }^{1,+}{ }^{+}$, Ruihong Zhang ${ }^{2,+}{ }^{\dagger}$, Stella Chin-Shaw Tsai ${ }^{3,4}{ }^{\oplus}$, Ruey-Hwang Chou ${ }^{5,6,7,8}$, Yi-Chao Hsu ${ }^{9} \mathbb{D}^{1}$, \\ Hueng-Chuen Fan ${ }^{1,10,11,12 \mathbb{D}}$, Chih-Hsin Muo ${ }^{13}$, Chung Y. Hsu ${ }^{14}$ and Kuang-Hsi Chang $1,15,16, * \mathbb{B}$
}

1 Department of Medical Research, Tungs' Taichung MetroHarbor Hospital, Taichung 435, Taiwan; hlchen0519@gmail.com (H.-L.C.); fanhuengchuen@yahoo.com.tw (H.-C.F.)

2 Department of Researching and Teaching, The Fourth Central Hospital of Baoding City, Tang County, Baoding 072350, China; zhangruihongdyx@163.com

3 Department of Otolaryngology, Tungs' Taichung MetroHarbor Hospital, Taichung 435, Taiwan; tsaistella111@gmail.com

4 Rong Hsing Research Center for Translational Medicine, College of Life Sciences, National Chung Hsing University, Taichung 402, Taiwan

5 Graduate Institute of Biomedical Sciences, China Medical University, Taichung 404, Taiwan; rhchou@mail.cmu.edu.tw

6 The Ph.D. Program of Biotechnology and Biomedical Industry, China Medical University, Taichung 404, Taiwan

7 Center for Molecular Medicine, China Medical University Hospital, Taichung 404, Taiwan

Citation: Chen, H.-L.; Zhang, R.; Tsai, S.C.-S.; Chou, R.-H.; Hsu, Y.-C.; Fan, H.-C.; Muo, C.-H.; Hsu, C.Y.; Chang, K.-H. Ambient Air Pollution Exposure and Risk of Developmental Delay in Children and Teenagers in Taiwan. Atmosphere 2021, 12, 1039. https://doi.org/10.3390/ atmos12081039

Academic Editors: Azhar Siddique, Mirza M. Hussain and Haider A. Khwaja

Received: 13 July 2021

Accepted: 10 August 2021

Published: 13 August 2021

Publisher's Note: MDPI stays neutral with regard to jurisdictional claims in published maps and institutional affiliations.

Copyright: (c) 2021 by the authors. Licensee MDPI, Basel, Switzerland. This article is an open access article distributed under the terms and conditions of the Creative Commons Attribution (CC BY) license (https:/ / creativecommons.org/licenses/by/ $4.0 /)$.
8 Department of Medical Laboratory and Biotechnology, Asia University, Taichung 413, Taiwan

9 Institute of Biomedical Sciences, Mackey Medical College, New Taipei City 252, Taiwan; hsuyc@mmc.edu.tw

10 Department of Pediatrics, Department of Medical Research, Tungs' Taichung Metroharbor Hospital, Taichung 435, Taiwan

11 Department of Rehabilitation, Jen-Teh Junior College of Medicine, Nursing and Management, Miaoli 356, Taiwan

12 Department of Life Sciences, Agricultural Biotechnology Center, National Chung Hsing University, Taichung 402, Taiwan

13 Management Office for Health Data, China Medical University Hospital, Taichung 404, Taiwan; b8507006@gmail.com

14 Graduate Institute of Clinical Medical Science, China Medical University, Taichung 404, Taiwan; hsucy63141@gmail.com

15 Center for General Education, China Medical University, Taichung 404, Taiwan

16 General Education Center, Jen-Teh Junior College of Medicine, Nursing and Management, Miaoli 356, Taiwan

* Correspondence: kuanghsichang@gmail.com; Tel.: +886-932-971-386

+ First authors, Hung-Lin Chen and Ruihong Zhang have contributed equally to this work.

\begin{abstract}
Background: Studies on the association between air pollution and developmental delay in children are limited. Therefore, we evaluated the risk of developmental delay in Taiwanese children exposed to air pollution. (2) Methods: We merged the two nationwide databases, and the annual average pollutant concentrations were grouped into tertiles to evaluate the risk of developmental delay (ICD-9 code 315.9). We identified the patients' active residential locations based on the location of the clinic or hospital in which they sought treatment for acute upper respiratory infections (ICD 9 code 460). The two nationwide databases were linked for analysis based on the active residential locations of each participant and the locations of the 74 ambient air quality monitoring stations. (3) Results: We observed an increased risk of developmental delay in children and teenagers exposed to $\mathrm{SO}_{2}, \mathrm{CO}$, and $\mathrm{NO}_{2}$. The adjusted odds ratios (ORs) of developmental delay for comparison among the tertiles with respect to $\mathrm{SO}_{2}, \mathrm{CO}$, and $\mathrm{NO}_{2}$ exposures were 1.12 (95\% confidence interval [CI], 1.01-1.24), 1.21 (95\% CI, 1.09-1.34), and 1.40 (95\% CI, 1.261.55), respectively. (4) Conclusions: The present findings suggest that air pollution exposure increases the risk of developmental delay in children and teenagers in Taiwan.
\end{abstract}

Keywords: ambient air pollution exposure; developmental delay; nationwide databases; acute upper respiratory infections 


\section{Introduction}

Ambient air pollution, especially due to traffic emissions, is closely related to human economic activity [1,2]. Increasing evidence indicates that long-term exposure to air pollution causes morbidity and mortality [3-10]. Based on the criteria set by the US Environmental Protection Agency (EPA), air pollutants include solid and gaseous components $[11,12]$. Extensive evidence has demonstrated that long-term exposure to particulate matter (PM) may be associated with children's development, such as birth weight, risk of hospitalization for respiratory infections or asthma, decline in lung function, and wheezing [13-17]. Several animal studies demonstrated that exposure to nitrogen oxide restricted their recovery from nerve trauma $[18,19]$. Long-term exposure to carbon monoxide (CO) may cause depression, confusion, memory loss, and cognitive decline in adults. Previous studies have focused on the association between PM, NOx, and neuropsychological development, such as intelligence quotient (IQ), executive functions, memory, visual motor abilities, academic skills, behavioral problems, autism spectrum disorder, and attention deficit hyperactivity disorder [20-27]. In contrast to the aforementioned findings, limited evidence was encountered for correlation between sulfur dioxide $\left(\mathrm{SO}_{2}\right)$, carbon monoxide $(\mathrm{CO})$, and developmental delays. Therefore, we merged two nationwide databases to evaluate the risk of developmental delays (DD) in children and teenagers exposed to nitrogen dioxide $\left(\mathrm{NO}_{2}\right), \mathrm{SO}_{2}$, and $\mathrm{CO}$.

\section{Materials and Methods}

\subsection{Data Source}

We used two datasets for this case-control study analysis: one included a database of children, and the other included an air quality database. The database included one-half of children (age $<18$ years) who were randomly selected from the Taiwan National Health Insurance (TNHI) program based on their birth year. The population in the database was limited to less than $10 \%$ of that of the THNI program to protect personal information, based on the guidelines (https:/ / nhird.nhri.org.tw /apply_04.html) (accessed date: 12 August 2021). The TNHI program covered over $99 \%$ of the populace because all Taiwanese were obligated to join this program. The database of children contained all medical claims and medical treatments from 1996 to 2012. Disease in the children's database was identified based on the International Classification of Disease, 9th Revision, Clinical Modification (ICD-9-CM), which was established by the World Health Organization. The information included in the air quality database was collected from 74 ambient air quality monitoring stations in Taiwan by Taiwan's Environmental Protection Agency. According to the Personal Information Protection Act, this study was approved by the Research Ethics Committee of China Medical University and Hospital (CMUH104-REC2-115).

\subsection{Study Subjects}

We selected children who were newly diagnosed with DD (ICD-9-CM 315) from 2006 to 2012 as the DD group. Four comparisons were randomly selected for children without DD diagnosis from the database based on age, gender, and DD diagnosis year. The year of index date of the control group was selected from the non-DD insured children in the same year as the corresponding children in the case group. The date of the year was randomly assigned to the control group.

\subsection{Exposure Assessment}

Cough (ICD-9-CM 460) is a usual symptom in children [28]. Thus, we defined the residential area of children and teenagers based on the most frequent hospital location for caring for the common cold. For example, if resident A went to Hospital B twice for a cold diagnosis (ICD-9-CM 460) and to Hospital C once, then his residential area would be the location of Hospital C. The ambient air quality monitoring stations located in their residential areas were used to calculate the exposure to air pollutants. The locations of the ambient air quality monitoring stations were based on the population density. There were 
$31,15,23$, and 5 ambient air quality monitoring stations in northern, central, southern, and eastern Taiwan, respectively. We enrolled children and teenagers residing in areas with air quality monitoring stations. The children and teenagers were assigned pollutant-exposure levels based on the data gained from the monitoring station present in their residential area. Daily average concentrations of air pollutants were calculated within five years before the SD diagnosis date and were grouped into tertiles with two cut-off points (33rd and 66th percentiles) as follows: $\mathrm{SO}_{2}$ concentration (low: $<3.77 \mathrm{ppb}$, medium: $3.77-5.30 \mathrm{ppb}$, and high: $>5.30 \mathrm{ppb}$ ); $\mathrm{CO}$ concentration (low: $<0.53 \mathrm{ppm}$, medium: $0.53-0.68 \mathrm{ppm}$, and high: $>0.68 \mathrm{ppm}$ ); $\mathrm{NO}_{2}$ concentration (low: $<18.17 \mathrm{ppm}$, medium: $18.17-23.90 \mathrm{ppm}$, and high: $>23.90 \mathrm{ppm}$ )

\subsection{Demographics and Baseline Comorbidity}

Demographics included occupation (white collar, blue collar, and others) and urbanization. Based on Liu's report, we grouped the residential areas as follows: level 1 to 2 represented high urbanization, level 3 to 4 signified median urbanization, and level 5 to 7 was designated as low urbanization [29]. Baseline comorbidities included low birth weight (ICD-9-CM 764), premature birth (ICD-9-CM 765), and Tourette syndrome (ICD-9-CM 307.2).

\subsection{Statistical Analysis}

Categorical variables are presented as numbers and percentages, and continuous variables are shown as mean(s) and standard deviation(s). The variation in categorical and continuous variables between the two groups was tested using the chi-square test and $t$-test. We performed multiple logistic regressions of DD to evaluate odds ratios (ORs) with $95 \%$ confidence intervals (CIs) in medium-high daily average concentrations of air pollutants, which were compared with the corresponding low concentrations. The multivariable models were adjusted for age, sex, urbanization, type of parental occupation, low birth weight, premature birth, and Tourette syndrome.

\section{Results}

We enrolled 14,745 children and teenagers during the study period. In total, 2888 participants were diagnosed with DD (ICD-9-CM 355) and were frequency-matched with 11,857 subjects without DD history based on age, sex, and DD diagnosis year. The distributions of age, sex, and parental occupation were not statistically different between the DD group and the comparison group. White collar was the most common parental occupation $(65.5 \%)$. The prevalence of comorbidities, such as low birth weight, premature birth, and Tourette syndrome were significantly higher at $0.8 \%, 4.2 \%$, and $1.1 \%$, respectively, in the DD group than in the group without DD history (Table 1).

Table 2 presents the multiple logistic regressions by stratification of comorbidities (low birth weight, premature birth, and Tourette syndrome). When participants were stratified by comorbidities, the ORs of DD were statistically higher at high levels of $\mathrm{SO} 2$ concentration compared with that of the low level group without low birth weight and Tourette syndrome; the adjusted $\mathrm{ORs}(\mathrm{aOR})$ were $1.12(95 \% \mathrm{CI}=1.01-1.24)$ and $1.01(95 \% \mathrm{CI}=1.01-1.23)$, respectively. Among the tertiles of $\mathrm{CO}$ concentration, the ORs of DD were statistically higher in the high $\mathrm{CO}$ concentration group than in the low group in all participants without comorbidities (without low birth weight: aOR $=1.21,95 \% \mathrm{CI}=1.09-1.34$; without premature birth: $\mathrm{aOR}=1.17,95 \% \mathrm{CI}=1.06-1.30$; without Tourette syndrome: $\mathrm{aOR}=1.20,95 \% \mathrm{CI}=1.09-1.33$ ). Among the tertiles of $\mathrm{NO} 2$ concentration, in participants without low birth weight, the aORs in the medium and high groups compared with that in the low group were 1.26 $(95 \% \mathrm{CI}=1.14-1.40)$ and $1.40(95 \% \mathrm{CI}=1.26-1.56)$, respectively. In participants without premature birth, compared to the low group, the aORs in the medium and high groups were $1.25(95 \% \mathrm{CI}=1.12-1.39)$ and $1.36(95 \% \mathrm{CI}=1.22-1.51)$, respectively. In participants without Tourette syndrome, the aORs in the medium and high groups compared with those in the low group were $1.27(95 \% \mathrm{CI}=1.14-1.40)$ and $1.39(95 \% \mathrm{CI}=1.25-1.54)$, respectively. 
Table 1. Distribution of demographic data among the study population.

\begin{tabular}{|c|c|c|c|c|c|c|c|c|}
\hline & & \multicolumn{2}{|c|}{ Without DD $(n=11,857)$} & \multicolumn{2}{|c|}{ With DD $(n=2888)$} & $p$ & \multicolumn{2}{|c|}{$\begin{array}{c}\text { Total } \\
(n=14,745)\end{array}$} \\
\hline Age (years) & Mean \pm SD & \multicolumn{2}{|c|}{$8.07 \pm 2.04$} & \multicolumn{2}{|c|}{$8.10 \pm 2.03$} & 0.479 & \multicolumn{2}{|c|}{$8.08 \pm 2.04$} \\
\hline Male & & 8523 & $71.9 \%$ & 2074 & $71.8 \%$ & 0.961 & 10,597 & $71.9 \%$ \\
\hline \multicolumn{9}{|l|}{ Urbanization } \\
\hline & High & 7492 & $63.2 \%$ & 2033 & $70.4 \%$ & $<0.001$ & 9525 & $64.6 \%$ \\
\hline & Medium & 3520 & $29.7 \%$ & 717 & $24.8 \%$ & & 4237 & $28.7 \%$ \\
\hline & Low & 845 & $7.1 \%$ & 138 & $4.8 \%$ & & 983 & $6.7 \%$ \\
\hline \multicolumn{9}{|c|}{ Parental occupation } \\
\hline & White-collar & 7752 & $65.4 \%$ & 1911 & $66.2 \%$ & 0.506 & 9663 & $65.5 \%$ \\
\hline & Blue-collar & 2268 & $19.1 \%$ & 525 & $18.2 \%$ & & 2793 & $18.9 \%$ \\
\hline & Others & 1837 & $15.5 \%$ & 452 & $15.7 \%$ & & 2289 & $15.5 \%$ \\
\hline Low bi & ight & 49 & $0.4 \%$ & 23 & $0.8 \%$ & 0.012 & 72 & $0.5 \%$ \\
\hline Prema & rth & 304 & $2.6 \%$ & 122 & $4.2 \%$ & $<0.001$ & 426 & $2.9 \%$ \\
\hline Tourett & ome & 34 & $0.3 \%$ & 33 & $1.1 \%$ & $<0.001$ & 67 & $0.5 \%$ \\
\hline \multicolumn{9}{|c|}{ Yearly average of $\mathrm{SO}_{2}(\mathrm{ppb})$} \\
\hline & Low & 3993 & $33.7 \%$ & 922 & $31.9 \%$ & 0.004 & 4915 & $33.3 \%$ \\
\hline & Medium & 3988 & $33.6 \%$ & 927 & $32.1 \%$ & & 4915 & $33.3 \%$ \\
\hline & High & 3876 & $32.7 \%$ & 1039 & $36.0 \%$ & & 4915 & $33.3 \%$ \\
\hline \multicolumn{9}{|c|}{ Yearly average of CO (ppm) } \\
\hline & Low & 4049 & $34.1 \%$ & 866 & $30.0 \%$ & $<0.001$ & 4915 & $33.3 \%$ \\
\hline & Medium & 3951 & $33.3 \%$ & 964 & $33.4 \%$ & & 4915 & $33.3 \%$ \\
\hline & High & 3857 & $32.5 \%$ & 1058 & $36.6 \%$ & & 4915 & $33.3 \%$ \\
\hline \multicolumn{9}{|c|}{ Yearly average of $\mathrm{NO}_{2}(\mathrm{ppb})$} \\
\hline & Low & 4117 & $34.7 \%$ & 798 & $27.6 \%$ & $<0.001$ & 4915 & $33.3 \%$ \\
\hline & Medium & 3923 & $33.1 \%$ & 992 & $34.3 \%$ & & 4915 & $33.3 \%$ \\
\hline & High & 3817 & $32.2 \%$ & 1098 & $38.0 \%$ & & 4915 & $33.3 \%$ \\
\hline
\end{tabular}

DD: developmental delays. SD: standard deviation.

Table 2. Adjusted odds ratios for development delays stratified by low birth weight, premature birth, and Tourette syndrome.

\begin{tabular}{|c|c|c|c|c|c|c|c|}
\hline & \multirow{2}{*}{$\begin{array}{l}\text { Pollutant } \\
\text { Levels }\end{array}$} & \multicolumn{2}{|c|}{$\mathrm{SO}_{2}$} & \multicolumn{2}{|c|}{$\mathrm{CO}$} & \multicolumn{2}{|c|}{$\mathrm{NO}_{2}$} \\
\hline & & aOR & $95 \%$ CI & aOR & $95 \% \mathrm{CI}$ & aOR & $95 \%$ CI \\
\hline \multicolumn{8}{|c|}{ Low birth weight } \\
\hline \multirow[t]{3}{*}{ no } & Low & 1.00 & & 1.00 & & 1.00 & \\
\hline & Medium & 0.98 & $0.89-1.09$ & 1.10 & $0.99-1.22$ & 1.26 & $1.14-1.40$ \\
\hline & High & 1.12 & $1.01-1.24$ & 1.21 & $1.09-1.34$ & 1.40 & $1.26-1.56$ \\
\hline \multirow[t]{3}{*}{ Yes } & Low & 1.00 & & 1.00 & & 1.00 & \\
\hline & Medium & 0.09 & $0.01-0.61$ & 0.77 & $0.16-3.61$ & 0.83 & $0.19-3.62$ \\
\hline & High & 0.52 & $0.14-1.93$ & 0.72 & $0.18-2.86$ & 0.81 & $0.20-3.32$ \\
\hline \multicolumn{8}{|c|}{ Premature birth } \\
\hline \multirow[t]{3}{*}{ no } & Low & 1.00 & & 1.00 & & 1.00 & \\
\hline & Medium & 0.95 & $0.86-1.06$ & 1.08 & $0.98-1.20$ & 1.25 & $1.12-1.39$ \\
\hline & High & 1.10 & $0.99-1.22$ & 1.17 & $1.06-1.30$ & 1.36 & $1.22-1.51$ \\
\hline \multirow[t]{3}{*}{ Yes } & Low & 1.00 & & 1.00 & & 1.00 & \\
\hline & Medium & 1.57 & $0.91-2.71$ & 1.80 & $1.02-3.18$ & 1.72 & $0.98-3.02$ \\
\hline & High & 1.68 & $0.98-2.87$ & 2.71 & $1.54-4.77$ & 2.87 & $1.62-5.10$ \\
\hline \multicolumn{8}{|c|}{ Tourette syndrome } \\
\hline \multirow[t]{3}{*}{ no } & Low & 1.00 & & 1.00 & & 1.00 & \\
\hline & Medium & 0.97 & $0.87-1.07$ & 1.11 & $1.00-1.23$ & 1.27 & $1.14-1.40$ \\
\hline & High & 1.11 & $1.01-1.23$ & 1.20 & $1.09-1.33$ & 1.39 & $1.25-1.54$ \\
\hline \multirow[t]{3}{*}{ Yes } & Low & 1.00 & & 1.00 & & 1.00 & \\
\hline & Medium & 2.09 & $0.50-8.72$ & 0.63 & $0.16-2.54$ & 1.03 & $0.25-4.33$ \\
\hline & High & 2.72 & $0.69-10.79$ & 2.39 & $0.60-9.52$ & 3.87 & $0.84-17.83$ \\
\hline
\end{tabular}

aOR: adjusted odds ratio; adjusted for age, sex, urbanization, and parental occupation. CI: confidence interval.

After adjusting for age, sex, urbanization level, type of parental occupation, and comorbidities of low birth weight, premature birth, and Tourette syndrome, multiple logistic regression analysis revealed that in comparison with the low group of the corresponding air pollutants, the aORs of DD for medium and high $\mathrm{SO}_{2}$ were $0.97(95 \% \mathrm{CI}=0.88-1.08)$ and $1.12(95 \% \mathrm{CI}=1.01-1.24)$; for medium and high $\mathrm{CO}$ were $1.10(95 \% \mathrm{CI}=1.00-1.22)$ and $1.21(95 \% \mathrm{CI}=1.09-1.34)$; and for medium and high $\mathrm{NO}_{2}$ were $1.26(95 \% \mathrm{CI}=1.14-1.40)$ and $1.40(95 \% \mathrm{CI}=1.26-1.55)$, respectively (Table 3$)$. 
Table 3. Adjusted odds ratios for development delays and associated air exposure.

\begin{tabular}{|c|c|c|c|c|c|c|c|c|}
\hline & & \multirow{2}{*}{ cOR } & \multicolumn{2}{|c|}{ Model 1} & \multicolumn{2}{|c|}{ Model 2} & \multicolumn{2}{|c|}{ Model 3} \\
\hline & & & aOR & $95 \%$ CI & aOR & $95 \%$ CI & aOR & $95 \%$ CI \\
\hline Age & & 1.01 & 1.01 & $0.99-1.03$ & 1.01 & $0.99-1.03$ & 1.01 & $0.99-1.03$ \\
\hline \multicolumn{9}{|l|}{ Sex } \\
\hline & Male & 1.00 & 1.00 & & 1.00 & & 1.00 & \\
\hline & Female & 1.00 & 1.01 & $0.92-1.10$ & 1.01 & $0.92-1.10$ & 1.01 & $0.92-1.10$ \\
\hline \multicolumn{9}{|c|}{ Urbanization } \\
\hline & High & 1.00 & 1.00 & & 1.00 & & 1.00 & \\
\hline & Medium & 0.71 & 0.75 & $0.68-0.82$ & 0.76 & $0.70-0.84$ & 0.78 & $0.70-0.85$ \\
\hline & Low & 0.60 & 0.62 & $0.51-0.75$ & 0.63 & $0.52-0.77$ & 0.67 & $0.55-0.81$ \\
\hline \multicolumn{9}{|c|}{ Parental occupation } \\
\hline & $\begin{array}{l}\text { White- } \\
\text { collar }\end{array}$ & 1.00 & 1.00 & & 1.00 & & 1.00 & \\
\hline & $\begin{array}{l}\text { Blue- } \\
\text { collar }\end{array}$ & 0.94 & 0.99 & $0.88-1.10$ & 0.99 & $0.89-1.11$ & 1.01 & $0.90-1.13$ \\
\hline & Others & 1.00 & 1.05 & $0.94-1.18$ & 1.06 & $0.94-1.19$ & 1.06 & $0.94-1.19$ \\
\hline \multicolumn{9}{|c|}{ Low birth weight } \\
\hline & No & 1.00 & 1.00 & & 1.00 & & 1.00 & \\
\hline & Yes & 1.94 & 1.46 & $0.87-2.43$ & 1.44 & $0.86-2.41$ & 1.45 & $0.87-2.42$ \\
\hline \multicolumn{9}{|c|}{ Premature birth } \\
\hline & No & 1.00 & 1.00 & & 1.00 & & 1.00 & \\
\hline & Yes & 1.68 & 1.64 & $1.32-2.04$ & 1.64 & $1.32-2.05$ & 1.64 & $1.32-2.05$ \\
\hline \multicolumn{9}{|c|}{ Tourette syndrome } \\
\hline & No & 1.00 & 1.00 & & 1.00 & & 1.00 & \\
\hline & Yes & 4.02 & 3.95 & $2.44-6.40$ & 3.93 & $2.43-6.38$ & 3.92 & $2.42-6.36$ \\
\hline \multicolumn{9}{|l|}{$\mathrm{SO}_{2}$} \\
\hline & Medium & 1.01 & 0.97 & $0.88-1.08$ & & & & \\
\hline \multirow{2}{*}{\multicolumn{9}{|c|}{$\mathrm{CO}$}} \\
\hline & & & & & & & & \\
\hline & Low & 1.00 & & & 1.00 & & & \\
\hline & Medium & 1.14 & & & 1.10 & $1.00-1.22$ & & \\
\hline & High & 1.28 & & & 1.21 & $1.09-1.34$ & & \\
\hline \multicolumn{8}{|l|}{$\mathrm{NO}_{2}$} & \\
\hline & Medium & 1.31 & & & & & 1.26 & $1.14-1.40$ \\
\hline & High & 1.48 & & & & & 1.40 & $1.26-1.55$ \\
\hline
\end{tabular}

COR: crude odds ratio. aOR: adjusted odds ratio. CI: confidence interval.

In addition, we performed multivariate analysis without considering the three covariates (low birth weight, premature birth, and Tourette syndrome) to minimize collider bias (Table 4). In comparison with the low group of the corresponding air pollutants, the aORs of $\mathrm{DD}$ for medium and high $\mathrm{SO}_{2}$ were $0.97(95 \% \mathrm{CI}=0.88-1.08)$ and $1.12(95 \% \mathrm{CI}=1.01-1.23)$; for medium and high CO were $1.10(95 \% \mathrm{CI}=1.00-1.22)$ and $1.21(95 \% \mathrm{CI}=1.09-1.34)$; and for medium and high $\mathrm{NO}_{2}$ were $1.27(95 \% \mathrm{CI}=1.14-1.41)$ and $1.40(95 \% \mathrm{CI}=1.26-1.55)$, respectively.

Table 4. Adjusted odds ratios for development delays and associated air exposure (without considering low birth weight, premature birth, and Tourette syndrome).

\begin{tabular}{ccccccc}
\hline & cOR & $\mathbf{9 5 \%} \mathbf{C I}$ & $p$ & aOR & $\mathbf{9 5 \% ~ C I ~}$ & $p$ \\
\hline $\mathrm{SO}_{2}$ & & & & & & \\
Low & 1.00 & & & 1.00 & & \\
Medium & 1.01 & $0.91-1.11$ & 0.897 & 0.97 & $0.88-1.08$ & 0.594 \\
High & 1.16 & $1.06-1.28$ & 0.003 & 1.12 & $1.01-1.23$ & 0.031 \\
CO & & & & & & \\
Low & 1.00 & & & 1.00 & & \\
Medium & 1.14 & $1.03-1.26$ & 0.011 & 1.10 & $1.00-1.22$ & 0.060 \\
High & 1.28 & $1.16-1.42$ & $<0.001$ & 1.21 & $1.09-1.34$ & $<0.001$ \\
$\quad \mathrm{NO}_{2}$ & & & & & & \\
Low & 1.00 & & & 1.00 & & \\
Medium & 1.31 & $1.18-1.45$ & $<0.001$ & 1.27 & $1.14-1.41$ & $<0.001$ \\
High & 1.48 & $1.34-1.64$ & $<0.001$ & 1.40 & $1.26-1.55$ & $<0.001$ \\
\hline
\end{tabular}

COR: crude odds ratio; aOR: adjusted odds ratio, adjusted for age, sex, urbanization, and parental occupation. $\mathrm{CI}$ : confidence interval. 


\section{Discussion}

We included 2888 enrolled participants aged $<18$ years who were diagnosed with developmental delay (DD, ICD-9-CM 355) during the study period. This large-scale study revealed that children and teenagers who were exposed to $\mathrm{SO}_{2}, \mathrm{CO}$, and $\mathrm{NO}_{2}$ pollution were at an increased risk of DD. In the stratification analysis, there was no significant increase in the risk of DD among pollutant tertiles in the participants with comorbidities. This may be due to a few participants with low birth weight, premature birth, and Tourette syndrome.

The association between exposure to air pollution and systemic oxidative stress has been widely investigated [30-34]. The inhalation of $\mathrm{SO}_{2}$ causes bronchoconstriction, resulting in oxygen insufficiency and hypoxia $[35,36]$. The onset of hypoxia has been associated with inflammation and oxidative stress [37-40]. Previous evidence supports the idea that oxidative stress plays a key role in the development of neural systems [41-44]. $\mathrm{NO}_{2}$, is an infamous reactive nitrogen species (RNS), which can co-act with reactive oxygen species (ROS) and is associated with apoptosis [45,46]. CO has long been considered a harmful gas and is linked to memory loss, dementia, and cognitive decline [47,48]. However, the association between DD and CO remains scarce.

Our results demonstrated that preterm birth and Tourette syndrome were also associated with DD in children. Preterm births have been reportedly associated with DD [49]. Cognitive delay is the most common impairment in children with preterm birth. Furthermore, lower birth weight during preterm births is one of the predictors of global cognitive impairment in children younger than 5 years. In addition, a meta-analysis observed a higher incidence rate of neurobehavioral outcomes in very preterm and/or very low birth weight children [50]. The most notable cognitive problem in children with preterm births was attention. Furthermore, lower performance in verbal fluency, working memory, and cognitive flexibility was observed in preterm children.

Children with Tourette syndrome have increased motor excitability [51]. Combined with recent brain imaging studies, it was revealed that the symptoms of Tourette syndrome occurred from a delay in the development of key brain networks. Neuroinflammation plays an important role in the neurodevelopmental pathophysiology in Tourette syndrome [52]. Our findings are consistent with those of previous studies, indicating that our data is comparable to data from other studies.

We also observed that DD was associated with urbanization, which causes heavy traffic, leading to traffic-related air pollution and allergic diseases [53]. In addition, we found that urbanization was positively correlated with air pollution in Taiwan. Hence, the association between urbanization and DD may emanate from air pollution. Another possible linkage is medical convenience. Urbanization levels are highly correlated with medical convenience and air pollution. This may lead to potential bias and overestimation of the risk of DD. The Taiwan National Health Insurance (TNHI) program covered over $99 \%$ of the population and reduced healthcare costs in districts with low urbanization; health disparities between urban and rural areas have been overcome [54,55].

The effects of air pollution on children's development have been highly concerning. Prenatal exposure to $\mathrm{SO}_{2}, \mathrm{CO}$, and $\mathrm{NO}_{2}$ was considered a risk factor for neurological and cognitive deficits in children. In 1996, a study in the Czech Republic revealed a high risk of visual contrast sensitivity in children around a coal combustion region that generated high levels of pollutants, including $\mathrm{SO}_{2}$ [56]. They hypothesized that preterm exposure to air pollutants disrupts the fetal neurological development. In addition to $\mathrm{SO}_{2}, \mathrm{CO}$ is confirmed to be associated with developmental neurotoxicity [57]. In rats, prenatal $\mathrm{CO}$ exposure altered the electrophysiology of the peripheral nervous system, especially sodium currents. Since the alterations were related to sodium inactivation kinetics and equilibrium potential, $\mathrm{CO}$ exposure may affect ion channel maturation. Moreover, prenatal exposure to $\mathrm{NO}_{2}$ affects cognitive and motor development in infants and negatively affects neurological development in boys, especially memory, verbal, and cognition. Previous studies have shown that prenatal exposure to air pollutants, such as $\mathrm{SO}_{2}, \mathrm{CO}$, and $\mathrm{NO}_{2}$, is detrimental 
to children's development. Our results suggest a negative association between exposure to air pollutants and children's development.

The strength of our study is that it is a nationwide study. We used the NHIRD database, which is a complete medical record, and covers $99 \%$ of the Taiwanese population. Furthermore, the subject selection was unbiased. In addition, we combined the nationwide healthcare database with an environmental database to estimate air pollution exposure using a unique method developed in our previous study [48]. Briefly, people usually visit a neighborhood clinic when they experience mild upper respiratory symptoms. Thus, by examining the clinic's address, we located the subjects' area of residence, which can be combined with the corresponding air pollutant database.

However, our study has several limitations. First, in compliance with the Personal Data Protection Act, individual addresses were not made available from the TNHI program. People usually visit a neighborhood clinic when they experience mild upper respiratory symptoms. Thus, by examining the clinic's address, we located an area near the subjects' residence, which can be combined with the corresponding air pollutant database. Although this approach of exposure assessment is not sufficiently accurate, it helped us to test this hypothesis. Second, the study period was from 2006 to 2012. We did not enroll participants who were diagnosed with DD after the study period. Misclassification bias may underestimate DD risk. Third, children or teenagers without a cold diagnosis during the study period were not enrolled in this study. This might have resulted in underestimation of the DD risk. We speculated that healthy children and teenagers were likely to be exposed to low concentrations of air pollutants. Fourth, our study only presented a significant association between air pollutant areas and $\mathrm{DD}$, and we have no knowledge on whether the air pollutants directly cause DD. Therefore, we may have to investigate the causative effect of air pollutants on DD. In this regard, one prospective study that we can perform is to shift the children from the air pollution areas and follow up to check the prevalence of DD in these children.

\section{Conclusions}

The significance of our study is that we demonstrated a considerable association between air pollutants and DD in children. Hence, it is crucial to raise children in a less polluting environment during development. Moreover, the government should encourage people to use public transportation, subsidize enterprises and factories to improve emission equipment, enforce elimination of old automobiles and motorcycles, and strengthen initiatives for development of green energy.

Author Contributions: Conceptualization, K.-H.C.; methodology, K.-H.C. and C.-H.M.; software, C.-H.M.; validation, H.-L.C.; R.Z.; S.C.-S.T.; R.-H.C.; Y.-C.H.; H.-C.F.; C.-H.M.; C.Y.H.; K.-H.C.; formal analysis, K.-H.C. and C.-H.M.; investigation, K.-H.C. and C.-H.M.; resources, C.Y.H.; data curation, K.-H.C. and C.-H.M.; writing—original draft preparation, H.-L.C. and R.Z.; writingreview and editing, K.-H.C.; visualization, H.-L.C.; R.Z.; S.C.-S.T.; R.-H.C.; Y.-C.H.; H.-C.F.; C.-H.M.; C.Y.H.; K.-H.C.; supervision, K.-H.C.; project administration, K.-H.C., C.Y.H. and S.C.-S.T.; funding acquisition, K.-H.C., C.Y.H. and S.C.-S.T. All authors have read and agreed to the published version of the manuscript.

Funding: This study is supported in part by the Taiwan Ministry of Health and Welfare Clinical Trial Center (MOHW109-TDU-B-212-114004); MOST Clinical Trial Consortium for Stroke (MOST 108-2321B-039-003-), the Tseng-Lien Lin Foundation, Taichung, Taiwan; and Tung's Taichung MetroHarbor hospital research grant (TTMHH-R1100012).

Institutional Review Board Statement: Not applicable.

Informed Consent Statement: Not applicable.

Data Availability Statement: Data are available from the NHIRD published by Taiwan National Health Insurance Bureau. Due to the 'Personal Information Protection Act', data cannot be made publicly available (http:/ / nhird.nhri.org.tw/en/index.html) (accessed on 12 August 2021). 
Acknowledgments: We thank the staff of the Management Office for Health Data of China Medical University Hospital for their contributions to this study.

Conflicts of Interest: The authors declare no conflict of interest.

\section{References}

1. Davis, M.E.; Laden, F.; Hart, J.E.; Garshick, E.; Smith, T.J. Economic activity and trends in ambient air pollution. Environ. Health Perspect. 2010, 118, 614-619. [CrossRef] [PubMed]

2. Zhang, K.; Batterman, S. Air pollution and health risks due to vehicle traffic. Sci. Total Environ. 2013, 450-451, 307-316. [CrossRef]

3. Cohen, A.J.; Brauer, M.; Burnett, R.; Anderson, H.R.; Frostad, J.; Estep, K.; Balakrishnan, K.; Brunekreef, B.; Dandona, L.; Dandona, R.; et al. Estimates and 25-year trends of the global burden of disease attributable to ambient air pollution: An analysis of data from the Global Burden of Diseases Study 2015. Lancet 2017, 389, 1907-1918. [CrossRef]

4. Lelieveld, J.; Evans, J.S.; Fnais, M.; Giannadaki, D.; Pozzer, A. The contribution of outdoor air pollution sources to premature mortality on a global scale. Nature 2015, 525, 367-371. [CrossRef] [PubMed]

5. Block, M.L.; Calderon-Garciduenas, L. Air pollution: Mechanisms of neuroinflammation and CNS disease. Trends Neurosci. 2009, 32, 506-516. [CrossRef]

6. Atkinson, R.W.; Carey, I.M.; Kent, A.J.; van Staa, T.P.; Anderson, H.R.; Cook, D.G. Long-term exposure to outdoor air pollution and incidence of cardiovascular diseases. Epidemiology 2013, 24, 44-53. [CrossRef] [PubMed]

7. Gehring, U.; Heinrich, J.; Kramer, U.; Grote, V.; Hochadel, M.; Sugiri, D.; Kraft, M.; Rauchfuss, K.; Eberwein, H.G.; Wichmann, H.E. Long-term exposure to ambient air pollution and cardiopulmonary mortality in women. Epidemiology 2006, 17, 545-551. [CrossRef] [PubMed]

8. Tiotiu, A.I.; Novakova, P.; Nedeva, D.; Chong-Neto, H.J.; Novakova, S.; Steiropoulos, P.; Kowal, K. Impact of Air Pollution on Asthma Outcomes. Int. J. Environ. Res. Public Health 2020, 17, 6212. [CrossRef] [PubMed]

9. Chang, K.H.; Hsu, P.Y.; Lin, C.J.; Lin, C.L.; Juo, S.H.; Liang, C.L. Traffic-related air pollutants increase the risk for age-related macular degeneration. J. Investig. Med. 2019, 67, 1076-1081. [CrossRef] [PubMed]

10. Fan, H.C.; Chen, C.Y.; Hsu, Y.C.; Chou, R.H.; Teng, C.J.; Chiu, C.H.; Hsu, C.Y.; Muo, C.H.; Chang, M.Y.; Chang, K.H. Increased risk of incident nasopharyngeal carcinoma with exposure to air pollution. PLoS ONE 2018, 13, e0204568. [CrossRef] [PubMed]

11. Dickey, J.H. Part VII. Air pollution: Overview of sources and health effects. Dis. Mon. 2000, 46, 566-589. [CrossRef]

12. Lewtas, J. Air pollution combustion emissions: Characterization of causative agents and mechanisms associated with cancer, reproductive, and cardiovascular effects. Mutat. Res. 2007, 636, 95-133. [CrossRef]

13. Kim, E.; Park, H.; Park, E.A.; Hong, Y.C.; Ha, M.; Kim, H.C.; Ha, E.H. Particulate matter and early childhood body weight. Environ. Int. 2016, 94, 591-599. [CrossRef] [PubMed]

14. Lin, M.; Stieb, D.M.; Chen, Y. Coarse particulate matter and hospitalization for respiratory infections in children younger than 15 years in Toronto: A case-crossover analysis. Pediatrics 2005, 116, e235-e240. [CrossRef]

15. Roy, A.; Hu, W.; Wei, F.; Korn, L.; Chapman, R.S.; Zhang, J.J. Ambient particulate matter and lung function growth in Chinese children. Epidemiology 2012, 23, 464-472. [CrossRef]

16. Cui, X.; Li, Z.; Teng, Y.; Barkjohn, K.K.; Norris, C.L.; Fang, L.; Daniel, G.N.; He, L.; Lin, L.; Wang, Q.; et al. Association Between Bedroom Particulate Matter Filtration and Changes in Airway Pathophysiology in Children With Asthma. JAMA Pediatr. 2020, 174, 533-542. [CrossRef] [PubMed]

17. Jung, K.H.; Hsu, S.I.; Yan, B.; Moors, K.; Chillrud, S.N.; Ross, J.; Wang, S.; Perzanowski, M.S.; Kinney, P.L.; Whyatt, R.M.; et al. Childhood exposure to fine particulate matter and black carbon and the development of new wheeze between ages 5 and 7 in an urban prospective cohort. Environ. Int. 2012, 45, 44-50. [CrossRef]

18. Zhu, N.; Li, H.; Han, M.; Guo, L.; Chen, L.; Yun, Y.; Guo, Z.; Li, G.; Sang, N. Environmental nitrogen dioxide (NO2) exposure influences development and progression of ischemic stroke. Toxicol. Lett. 2012, 214, 120-130. [CrossRef]

19. Li, H.; Xin, X. Nitrogen dioxide $(\mathrm{NO}(2))$ pollution as a potential risk factor for developing vascular dementia and its synaptic mechanisms. Chemosphere 2013, 92, 52-58. [CrossRef]

20. Becerra, T.A.; Wilhelm, M.; Olsen, J.; Cockburn, M.; Ritz, B. Ambient air pollution and autism in Los Angeles county, California. Environ. Health Perspect. 2013, 121, 380-386. [CrossRef]

21. Volk, H.E.; Kerin, T.; Lurmann, F.; Hertz-Picciotto, I.; McConnell, R.; Campbell, D.B. Autism spectrum disorder: Interaction of air pollution with the MET receptor tyrosine kinase gene. Epidemiology 2014, 25, 44-47. [CrossRef]

22. Grandjean, P.; Landrigan, P.J. Neurobehavioural effects of developmental toxicity. Lancet Neurol. 2014, 13, 330-338. [CrossRef]

23. Guxens, M.; Sunyer, J. A review of epidemiological studies on neuropsychological effects of air pollution. Swiss Med. Wkly. 2012, 141, w13322. [CrossRef] [PubMed]

24. Perera, F.P.; Wang, S.; Rauh, V.; Zhou, H.; Stigter, L.; Camann, D.; Jedrychowski, W.; Mroz, E.; Majewska, R. Prenatal exposure to air pollution, maternal psychological distress, and child behavior. Pediatrics 2013, 132, e1284-e1294. [CrossRef]

25. Lovasi, G.S.; Eldred-Skemp, N.; Quinn, J.W.; Chang, H.W.; Rauh, V.A.; Rundle, A.; Orjuela, M.A.; Perera, F.P. Neighborhood Social Context and Individual Polycyclic Aromatic Hydrocarbon Exposures Associated with Child Cognitive Test Scores. J. Child. Fam. Stud. 2014, 23, 785-799. [CrossRef]

26. Gong, T.; Almqvist, C.; Bolte, S.; Lichtenstein, P.; Anckarsater, H.; Lind, T.; Lundholm, C.; Pershagen, G. Exposure to air pollution from traffic and neurodevelopmental disorders in Swedish twins. Twin Res. Hum. Genet. 2014, 17, 553-562. [CrossRef] 
27. Suades-Gonzalez, E.; Gascon, M.; Guxens, M.; Sunyer, J. Air Pollution and Neuropsychological Development: A Review of the Latest Evidence. Endocrinology 2015, 156, 3473-3482. [CrossRef]

28. Faniran, A.O.; Peat, J.K.; Woolcock, A.J. Measuring persistent cough in children in epidemiological studies: Development of a questionnaire and assessment of prevalence in two countries. Chest 1999, 115, 434-439. [CrossRef] [PubMed]

29. Liu, C.-Y.; Hung, Y.-T.; Chuang, Y.-L.; Chen, Y.-J.; Weng, W.-S.; Liu, J.-S.; Liang, K.-Y. Incorporating Development Stratification of Taiwan Townships into Sampling Design of Large Scale Health Interview Surve. J. Health Manag. 2006, 4, 1-22. [CrossRef]

30. Franchini, M.; Mannucci, P.M. Thrombogenicity and cardiovascular effects of ambient air pollution. Blood 2011, 118, 2405-2412. [CrossRef]

31. Brook, R.D.; Rajagopalan, S.; Pope, C.A., 3rd; Brook, J.R.; Bhatnagar, A.; Diez-Roux, A.V.; Holguin, F.; Hong, Y.; Luepker, R.V.; Mittleman, M.A.; et al. Particulate matter air pollution and cardiovascular disease: An update to the scientific statement from the American Heart Association. Circulation 2010, 121, 2331-2378. [CrossRef] [PubMed]

32. Nemmar, A.; Hoet, P.H.; Dinsdale, D.; Vermylen, J.; Hoylaerts, M.F.; Nemery, B. Diesel exhaust particles in lung acutely enhance experimental peripheral thrombosis. Circulation 2003, 107, 1202-1208. [CrossRef] [PubMed]

33. Lucking, A.J.; Lundback, M.; Mills, N.L.; Faratian, D.; Barath, S.L.; Pourazar, J.; Cassee, F.R.; Donaldson, K.; Boon, N.A.; Badimon, J.J.; et al. Diesel exhaust inhalation increases thrombus formation in man. Eur. Heart J. 2008, 29, 3043-3051. [CrossRef]

34. Nadel, J.A.; Tamplin, B.; Tokiwa, Y. Mechanism of Bronchoconstriction. During Inhalation of Sulfur Dioxide; Reflex Involving Vagus Nerves. Arch. Environ. Health 1965, 10, 175-178. [CrossRef] [PubMed]

35. Nadel, J.A.; Salem, H.; Tamplin, B.; Tokiwa, Y. Mechanism of Bronchoconstriction during Inhalation of Sulfur Dioxide. J. Appl. Physiol. 1965, 20, 164-167. [CrossRef] [PubMed]

36. Zhang, P.; Wang, Y.; Wang, H.; Cao, J. Sesamol alleviates chronic intermittent hypoxia-induced cognitive deficits via inhibiting oxidative stress and inflammation in rats. Neuroreport 2021, 32, 105-111. [CrossRef] [PubMed]

37. Rumman, M.; Pandey, S.; Singh, B.; Gupta, M.; Ubaid, S.; Mahdi, A.A. Genistein Prevents Hypoxia-Induced Cognitive Dysfunctions by Ameliorating Oxidative Stress and Inflammation in the Hippocampus. Neurotox. Res. 2021. [CrossRef] [PubMed]

38. Merelli, A.; Repetto, M.; Lazarowski, A.; Auzmendi, J. Hypoxia, Oxidative Stress, and Inflammation: Three Faces of Neurodegenerative Diseases. J. Alzheimers Dis. 2021, 82, S109-S126. [CrossRef]

39. McGarry, T.; Biniecka, M.; Veale, D.J.; Fearon, U. Hypoxia, oxidative stress and inflammation. Free Radic. Biol. Med. 2018, 125, 15-24. [CrossRef] [PubMed]

40. Migliore, L.; Coppede, F. Environmental-induced oxidative stress in neurodegenerative disorders and aging. Mutat. Res. 2009, 674, 73-84. [CrossRef]

41. Berr, C.; Balansard, B.; Arnaud, J.; Roussel, A.M.; Alpérovitch, A. Cognitive decline is associated with systemic oxidative stress: The EVA study. Etude du Vieillissement Artériel. J. Am. Geriatr. Soc. 2000, 48, 1285-1291. [CrossRef]

42. Bayir, H.; Kagan, V.E.; Tyurina, Y.Y.; Tyurin, V.; Ruppel, R.A.; Adelson, P.D.; Graham, S.H.; Janesko, K.; Clark, R.S.; Kochanek, P.M. Assessment of antioxidant reserves and oxidative stress in cerebrospinal fluid after severe traumatic brain injury in infants and children. Pediatr. Res. 2002, 51, 571-578. [CrossRef]

43. Hamed, S.A.; Hamed, E.A.; Zakary, M.M. Oxidative stress and S-100B protein in children with bacterial meningitis. BMC Neurol. 2009, 9, 51. [CrossRef]

44. Maher, P.; Schubert, D. Signaling by reactive oxygen species in the nervous system. Cell Mol. Life Sci. 2000, 57, 1287-1305 [CrossRef] [PubMed]

45. Emerit, J.; Edeas, M.; Bricaire, F. Neurodegenerative diseases and oxidative stress. Biomed. Pharm. 2004, 58, 39-46. [CrossRef] [PubMed]

46. Chen, H.L.; Chen, P.C.; Lu, C.H.; Hsu, N.W.; Chou, K.H.; Lin, C.P.; Wu, R.W.; Li, S.H.; Cheng, Y.F.; Lin, W.C. Structural and cognitive deficits in chronic carbon monoxide intoxication: A voxel-based morphometry study. BMC Neurol. 2013, 13, 129. [CrossRef] [PubMed]

47. Chang, K.H.; Chang, M.Y.; Muo, C.H.; Wu, T.N.; Chen, C.Y.; Kao, C.H. Increased risk of dementia in patients exposed to nitrogen dioxide and carbon monoxide: A population-based retrospective cohort study. PLoS ONE 2014, 9, e103078. [CrossRef] [PubMed]

48. Linsell, L.; Malouf, R.; Morris, J.; Kurinczuk, J.J.; Marlow, N. Prognostic Factors for Poor Cognitive Development in Children Born Very Preterm or With Very Low Birth Weight: A Systematic Review. JAMA Pediatr. 2015, 169, 1162-1172. [CrossRef]

49. Aarnoudse-Moens, C.S.; Weisglas-Kuperus, N.; van Goudoever, J.B.; Oosterlaan, J. Meta-analysis of neurobehavioral outcomes in very preterm and/or very low birth weight children. Pediatrics 2009, 124, 717-728. [CrossRef]

50. Pepes, S.E.; Draper, A.; Jackson, G.M.; Jackson, S.R. Effects of age on motor excitability measures from children and adolescents with Tourette syndrome. Dev. Cogn. Neurosci. 2016, 19, 78-86. [CrossRef]

51. Martino, D.; Johnson, I.; Leckman, J.F. What Does Immunology Have to Do With Normal Brain Development and the Pathophysiology Underlying Tourette Syndrome and Related Neuropsychiatric Disorders? Front. Neurol. 2020, 11, 567407. [CrossRef]

52. Carlsten, C.; Rider, C.F. Traffic-related air pollution and allergic disease: An update in the context of global urbanization. Curr. Opin. Allergy Clin. Immunol. 2017, 17, 85-89. [CrossRef]

53. Shou-Hsia, C.; Tung-Liang, C. The Effect of Universal Health Insurance on Health Care Utilization in Taiwan: Results From a Natural Experiment. JAMA 1997, 278, 89-93. [CrossRef]

54. Huang, N.; Yip, W.; Chang, H.J.; Chou, Y.J. Trends in rural and urban differentials in incidence rates for ruptured appendicitis under the National Health Insurance in Taiwan. Public Health 2006, 120, 1055-1063. [CrossRef] [PubMed] 
55. Hudnell, H.K.; Skalik, I.; Otto, D.; House, D.; Subrt, P.; Sram, R. Visual contrast sensitivity deficits in Bohemian children. Neurotoxicology 1996, 17, 615-628. [PubMed]

56. Carratu, M.R.; Cagiano, R.; De Salvia, M.A.; Trabace, L.; Cuomo, V. Developmental neurotoxicity of carbon monoxide. Arch. Toxicol. Suppl. 1995, 17, 295-301. [CrossRef] [PubMed]

57. Lertxundi, A.; Andiarena, A.; Martinez, M.D.; Ayerdi, M.; Murcia, M.; Estarlich, M.; Guxens, M.; Sunyer, J.; Julvez, J.; Ibarluzea, J. Prenatal exposure to PM2.5 and $\mathrm{NO}_{2}$ and sex-dependent infant cognitive and motor development. Environ. Res. 2019, 174, 114-121. [CrossRef] 